\title{
Measurements of Natural Radioactivity in Some Granite Samples Using Alpha Spectrometric Analysis
}

\author{
Hanan Mohamed Diab ${ }^{1}$, Mohamed Helmy Eweis Monged ${ }^{1}$, Mahmoud Khattab ${ }^{2}$ \\ ${ }^{1}$ Egyptian Nuclear and Radiological Regulatory Authority, Cairo, Egypt \\ ${ }^{2}$ Nuclear Materials Authority, Cairo, Egypt \\ Email: hnndiab@yahoo.co.uk, monged79@gmail.com
}

Received September 12, 2013; revised October 13, 2013; accepted October 21, 2013

Copyright (C) 2013 Hanan Mohamed Diab et al. This is an open access article distributed under the Creative Commons Attribution License, which permits unrestricted use, distribution, and reproduction in any medium, provided the original work is properly cited. In accordance of the Creative Commons Attribution License all Copyrights (C) 2013 are reserved for SCIRP and the owner of the intellectual property Hanan Mohamed Diab et al. All Copyright (C) 2013 are guarded by law and by SCIRP as a guardian.

\begin{abstract}
Alpha spectrometry using pulse height analysis has been used for the determination of uranium concentrations in different environmental samples. The concentration of ${ }^{238} \mathrm{U}$ was measured by both destructive and non-destructive techniques with a detection limit of less than $1.8 \mathrm{mBq} / \mathrm{kg}$. However, because of the extremely low ${ }^{234} \mathrm{U}$ concentrations in environmental samples, it was necessary to use a destructive technique to separate $U$ from the sample matrices as well as remove interfering elements from the sample solution to determine ${ }^{238} U /{ }^{234} U$ ratio. In this study, the uranium was separated from the environmental samples using anion exchangers in (Dowex $1 \times 8 \mathrm{Cl}^{-}$form) and purified via co-precipitation with Lanthanum fluorides $\left(\mathrm{LaF}_{3}\right)$ and the alpha source prepared by electrodeposition. The results obtained were validated using some certified reference samples.
\end{abstract}

Keywords: Uranium Separation; $\alpha$-Spectrometry; Alpha Pulse Height Analysis Isotopic Ratio; Granite Samples

\section{Introduction}

Uranium is a widely distributed lithophile metallic element. It may be present as a significant constituent in some minerals (e.g. uraninite, brannerite and carnotite) or as an accessory element in others (e.g. zircon, apatite, allanite and monazite). The natural uranium consists of three radioisotopes; ${ }^{238} \mathrm{U},{ }^{235} \mathrm{U}$ and ${ }^{234} \mathrm{U}$ with atomic abundances of approximately $99.275 \%, 0.72 \%$, and $0.0055 \%$ respectively. All three isotopes comprise the natural uranium and have the same geochemical behavior [1]. The uranium concentration and $\mathrm{U}$-isotopic ratios are usually detected and determined in various environmental, samples by different non-destructive and destructive techniques. The non-destructive techniques are mostly achieved by $\gamma$-spectrometry (e.g. NaI- and HPGe-detectors). They are carried out on the bulk samples without the need for complicated and time consuming radiochemical separations methods [2,3].

Moreover, the destructive techniques are carried out through several analytical methods (e.g. $\alpha$-spectrometry, fluorimetry, kinetic phosphorescence, neutron activation analysis, etc). Among these techniques, $\alpha$-spectrometry is the most common one that measures radioisotopes and can detect low uranium concentrations (below ng $1^{-1}$ ). Its detection limit is typically 100 to 1000 times lower than $\gamma$-spectrometry [4]. This technique is mostly used for detection and analysis of $U$ as well as Th radioisotopes, particularly in the environmental samples, such as natural waters, which are characterized with low radioactivity concentration levels $[3,5]$.

The procedure for alpha spectrometry is carried out through several steps including sample preparation, radiochemical separation, preparation of a thin alpha source, such as via electro-deposition or co-precipitation, and $\alpha$ counting employing high-resolution pulse height analysis [6-9]. Sample preparation aims to convert the sample into a thin layered, chemically isolated form that can be placed into the spectrometer and counted with a minimum alpha particle energy interferences and self absorption, and alpha peak broadening due to energy straggling with thick sources. It is often an extensive process and requires several steps including: 1) sample digestion (preliminary treatment); 2) uranium separation and purification 3) alpha source preparation, and 4) alpha counting over extended periods for low detection limits. The uranium separation is usually 
carried out using various techniques such as co-precipitation, liquid-liquid extraction, ion exchange and extraction chromatography. Three main methods are commonly used for preparation of the sample on a stainless steel disc (source preparation) namely; 1) direct evaporation from an organic solvent; 2) electro-deposition and 3) coprecipitation with NdF. The later method is more preferred technique but it requires careful preparative steps to eliminate organic material and to adjust the $\mathrm{pH}$ of the electrolyte. Several methods and flow charts have been reported in different literatures for sample preparation for $\mathrm{U}$-analysis using $\alpha$-spectrometry [6,10,11].

\section{Experimental Work}

\subsection{Non-Destructive Analysis}

Six granite samples were collected from eastern desert of Egypt and were prepared for destructive and nondestructive technique. For nondestructive analysis, the samples were mechanically pulverized and passed through 0.8 $\mathrm{mm}$ mesh sieve. Samples were collected using the standard methods to get composite sample that represents each site. The dried and sieved portion of the samples were transferred to Marinelli beakers of 100 or $1000 \mathrm{ml}$ volume and sealed at least for 4 weeks to reach secular equilibrium between radium and thorium, and their progenies. ${ }^{226} \mathrm{Ra}\left({ }^{238} \mathrm{U}\right.$ series $),{ }^{228} \mathrm{Ra}\left({ }^{232} \mathrm{Th}\right.$ series $)$, and $\mathrm{K}$ activities were measured using gamma-spectrometry based on hyperpure germanium detectors. The HPGe detector had a relative efficiency of $40 \%$ and full width at half maximum (FWHM) of $1.95 \mathrm{keV}$ for ${ }^{60} \mathrm{Co}$ gamma energy line at $1332 \mathrm{keV}$ and operated with Canberra Genie 2000 software for gamma acquisition and analysis. The gamma transmissions used for activity calculations were $351.9\left({ }^{214} \mathrm{~Pb}\right), 609.3,1120.3$ and $1764.5 \mathrm{keV}\left({ }^{214} \mathrm{Bi}\right)$ for the ${ }^{226} \mathrm{Ra}$ series, 338.4, 911.1 and $968.9 \mathrm{keV} \mathrm{Ac}$ ) for the Th-series and $1460.7 \mathrm{keV}$ for ${ }^{40} \mathrm{~K}$ presented in gamma specrtrum below in Figure 1. The gamma-spectrometers were calibrated using both ${ }^{226} \mathrm{Ra}$ point source and potassium chloride standard solutions in the same geometry as the samples [12].

\subsection{Destructive Analysis}

For destructive analysis, $10 \mathrm{~g}$ of ashed soil sample was spiked with uranium tracer $\left({ }^{232} \mathrm{U}\right)$ for chemical yield monitoring. The dried samples were ashed at $550^{\circ} \mathrm{C}$ for eight hours. The ashed sample was dissolved in $40 \mathrm{ml}$ of $65 \% \mathrm{HNO}_{3}, 15 \mathrm{ml}$ of $37 \% \mathrm{HCl}$ and $10 \mathrm{ml}$ of $40 \% \mathrm{HF}$ acids. Uranium in the dissolved sample solution was extracted from most of the matrix elements with $25 \mathrm{ml}$ of $0.2 \mathrm{M}$ TOPO/Cyclohexane (Trioctyl-phosphine oxide) and then back-extracted with $25 \mathrm{ml}$ of $1 \mathrm{M} \mathrm{NH}_{4} \mathrm{~F} / 0.1 \mathrm{M}$ $\mathrm{HCl}$ solution. The solution is co-precipitated by $\mathrm{LaF}_{3}(25$ $\mathrm{mg} / \mathrm{ml}$ of $\mathrm{La}\left(\mathrm{NO}_{3}\right)_{3}$ with $\mathrm{HF} 40 \%$ ). Then, the solution is centrifuged and the formed precipitate is dissolved in hot boric acid (saturated solution) and $\mathrm{HNO}_{3}$. The uranium is re-oxidized to the hexavalent state by adding $\mathrm{H}_{2} \mathrm{O}_{2}$. This followed by evaporation of the solution to dryness and the obtained residue is dissolved in $9 \mathrm{M} \mathrm{HCl}$, and then passed through a conditioned anion exchange resin column (15 cm long; its inner diameter is $8 \mathrm{~mm}$ ) at a flow rate of $1 \mathrm{ml} /$ minute. The used resin is $2 \mathrm{~g}$ Dowex $1 \times 8$ $\mathrm{Cl}^{-}$form, 50 - 100 mesh (strongly basic gel type polystyrene resin) with appropriate functional groups. To elute $\mathrm{U}$ from the column, $0.5 \mathrm{M}$ of $\mathrm{HNO}_{3}$ is passed through the column with a flow rate of $1 \mathrm{ml} /$ minute and the eluted $U$ is evaporated to dryness in a crystallizing dish using $1 \mathrm{ml}$ of concentrated $\mathrm{HCl}$. The eluted uranium is transferred into the electrolysis cell from the crystallization dish with $0.4 \mathrm{ml}$ of $4 \mathrm{M} \mathrm{HCl}$, three times by $1 \mathrm{ml}$ of $\left(\mathrm{NH}_{4}\right)_{2} \mathrm{C}_{2} \mathrm{O}_{4}(4 \%)$ and then once $0.6 \mathrm{ml}$ distilled water. The electrolysis is carried out for 3 hours at $300 \mathrm{~mA}(0.3$ A), and then $1 \mathrm{ml}$ of ammonia solution $\left(\mathrm{NH}_{4} \mathrm{OH}\right.$ with $25 \%$ conc.) is added. After one minute, the electrolysis current is cut off. The ammonia increases the $\mathrm{OH}$ concentration which prevents re-dissolution of the hydroxide from the cathode surface and then measured by alpha spectrometry [13]. Schematic radiochemical procedure of uranium is shown in Figure 2.

\subsection{Uncertainty Calculation}

The error associated with any particular counting result is determined by the use of the following equation.

$$
\sigma=\frac{\sqrt{N}}{t}=\sqrt{\left(\frac{N}{t^{2}}\right)}=\sqrt{\frac{r}{t}}
$$

where, $r$ : is the net count rate.

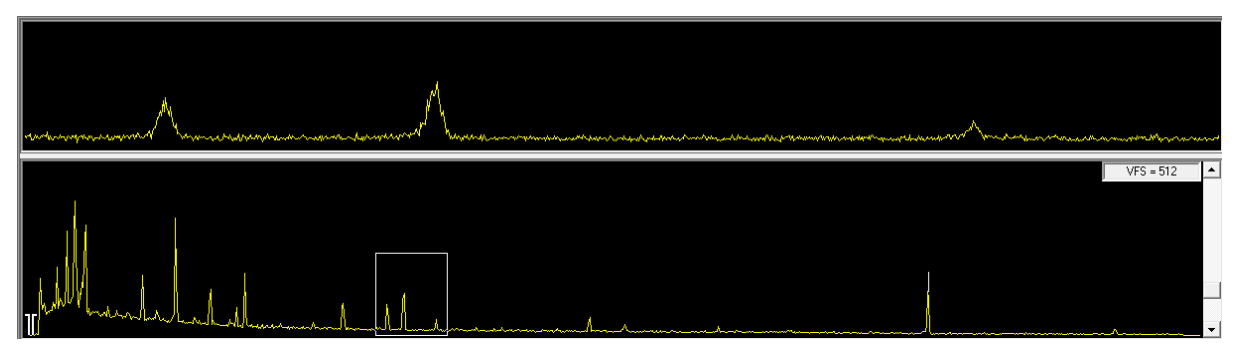

Figure 1. An example of gamma spectra. 


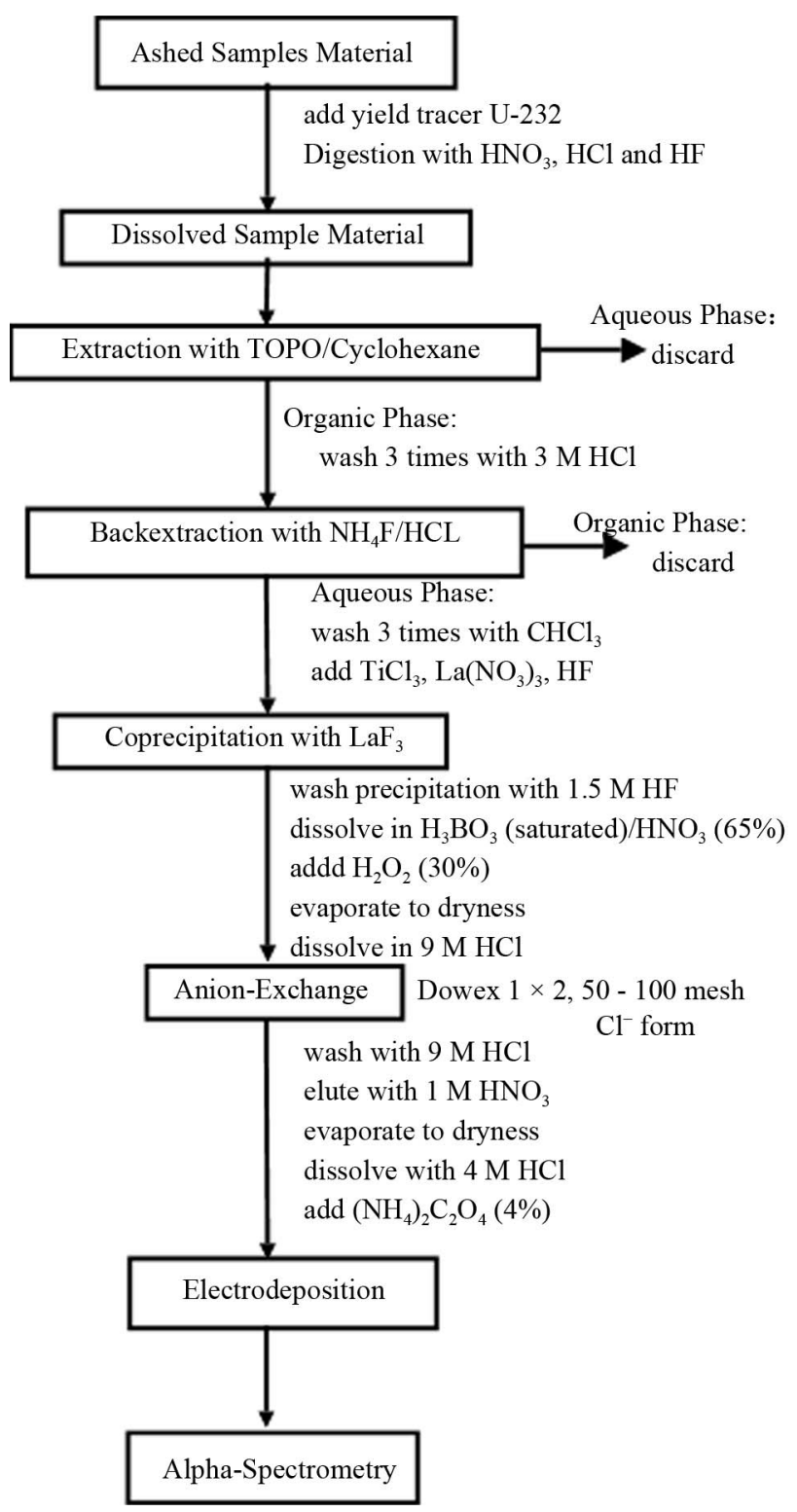

Figure 2. Schematic representation of the radiochemical procedure of uranium.

In this case we are interested in subtracting one count from another (gross counts minus background counts) and determining the resulting \% error of the NCPS (Net Count Per Second) based on the standard deviation $\sigma$ value. Counting instruments typically have a confidence interval of $95 \%$. Thus Equation (2) is written as:

$$
\sigma_{n}=\sqrt{\frac{r_{0 Y}}{t_{0}}+\frac{r_{s Y}}{t_{s}}}
$$

where,

$-r_{O Y}, r_{S Y}$ : are the net count rate at the gamma line $(Y)$ for the background and the sample respectively,

$-t_{o}, t_{s}$ : are the real counting time of the background and the sample respectively.

\subsection{Validation of the Method}

The precision and accuracy of the method were determined by analyzing reference materials: soil IAEA-326, IAEA-375 and sediment IAEA-300.The precision achieved was $6.7 \%$ for $\mathrm{U}$ isotopes. Typical lower limits of detection for the alpha measurements were $1.6 \mathrm{mBq} / \mathrm{kg}$ for ${ }^{238} \mathrm{U}$ and $1.8 \mathrm{mBq} / \mathrm{kg}$ for ${ }^{234} \mathrm{U}$. Blank samples and reagent blanks were processed and measured at the beginning of the analysis to batch to trace any cross contamination which might occur during the analysis steps. The data obtained shows good accuracy without any sign of cross contamination.

\subsection{Apparatus}

The alpha spectrometry system employed $450 \mathrm{~mm}^{2}$ silicon surface barrier detectors, (ORTEC model 576 A) with $450 \mathrm{~mm}^{2}$, USA. The silicon surface barrier detector was characterized by high resolution performance, low background, excellent stability and high permissible counting rates. The detector resolution was about $25 \mathrm{keV}$ for ${ }^{241} \mathrm{Am}$ and the detector efficiency was approximately $23 \%$ with no significant variation in the range interval $2.5-8.8$ $\mathrm{MeV}$. It was determined using the following equation:

$$
\eta=\frac{N}{A \cdot t_{c}}
$$

where, $\eta$ is the detector efficiency, $N$ is the counts of the alpha peak, $A$ is the activity of the radionuclide and $t_{c}$ is the counting time.

The system was vacuum controlled (anti-recoil) and controlled with ORTEC software for calculation of the radionuclide activity. The counting time used for measurements was 4 - 8 days, depending on the sample activity, to achieve a detection limit of about $0.002 \mathrm{~Bq}$ per sample. The counting time can be reduced by increasing sample weight, but it was found that it is cost effective because as the sample weight increase the chemicals and acids needed for digestion will increase and the time required for sample digestion will also increase. The measured ${ }^{238} \mathrm{U},{ }^{235} \mathrm{U}$ and ${ }^{234} \mathrm{U}$ activity concentrations were reported in $\mathrm{Bq} / \mathrm{kg}$ as shown in Figure 3. The chemical yield for the process involved in alpha sample analysis is around $70 \%$. The system energy calibration was performed with a mixed alpha source containing ${ }^{239} \mathrm{Pu}\left(\mathrm{E}_{\alpha}=5.1\right.$ $\mathrm{MeV}),{ }^{241} \mathrm{Am}\left(\mathrm{E}_{\alpha}=5.48 \mathrm{MeV}\right)$ and ${ }^{244} \mathrm{Cm}\left(\mathrm{E}_{\alpha}=5.8 \mathrm{MeV}\right)$ radionuclides. They have the same chemical composition, concentration, geometry as well as counting configuration. The detection limit of the $\alpha$-spectrometry was about as $0.002 \mathrm{~Bq}$ per sample $[14,15]$.

\section{Results and Discussion}

\subsection{Non-Destructive Analysis}

The three most common primordial radionuclides inves- 


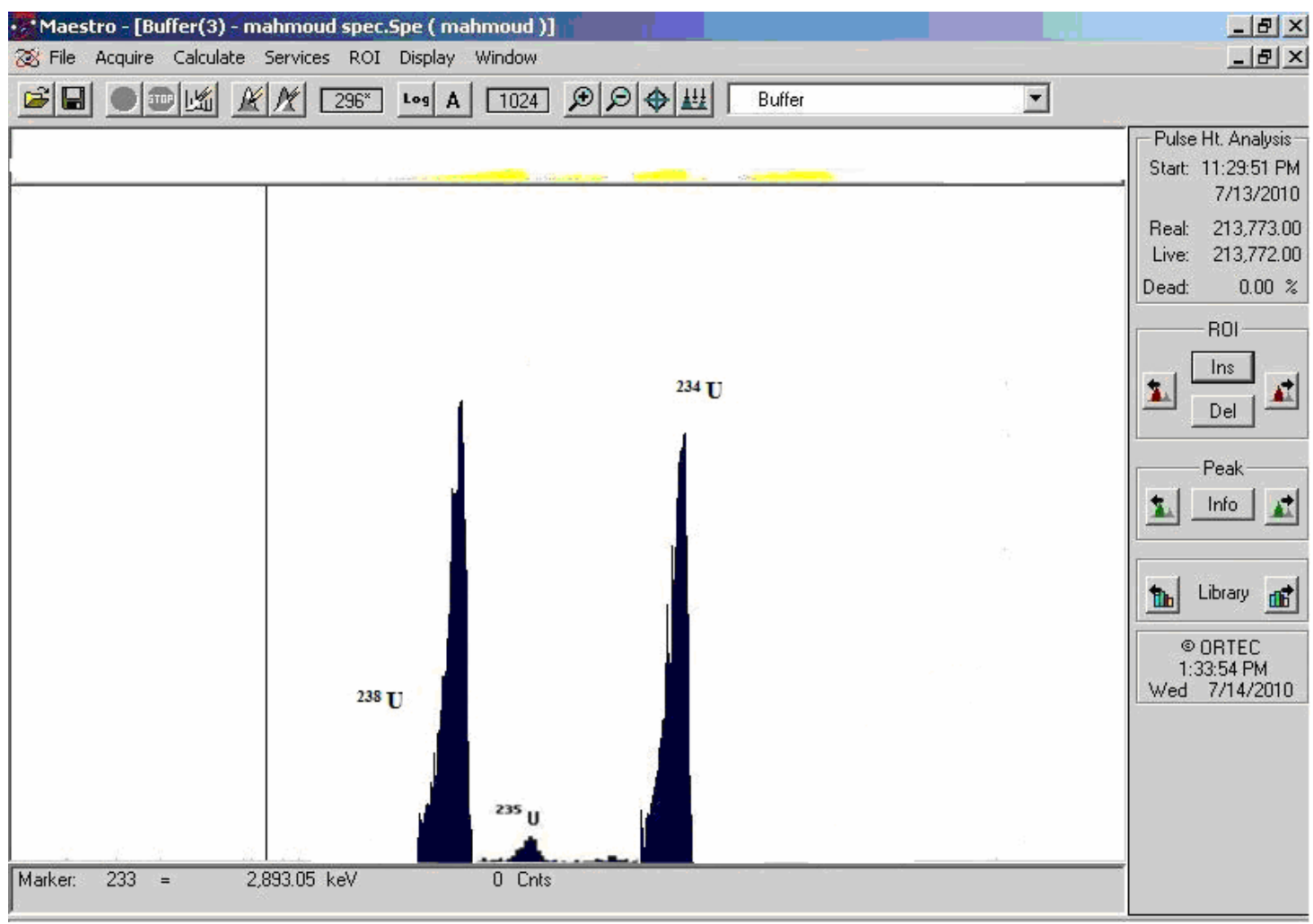

Figure 3. An example of U-isotopes measured by Alpha Spectrometer.

tigated in the study area were ${ }^{40} \mathrm{~K},{ }^{238} \mathrm{U}\left({ }^{226} \mathrm{Ra}\right)$ and ${ }^{232} \mathrm{Th}$. The tabulated activity for the naturally occurring radionuclides ${ }^{238} \mathrm{U}\left({ }^{226} \mathrm{Ra}\right)$ and ${ }^{232}$ Thare the average of the activities of most abundant photo peaks of the decay products of the uranium series $(351,609,1120,1764 \mathrm{keV})$ and thorium series $(238,583,911 \mathrm{keV})$. The specific activities of ${ }^{238} \mathrm{U},{ }^{232} \mathrm{Th}$ and ${ }^{40} \mathrm{~K}$ for the collected samples were shown in Table 1. ${ }^{238} \mathrm{U},{ }^{232} \mathrm{Th}$ and ${ }^{40} \mathrm{~K}$ concentrations ranged from 44.9 to $149 \mathrm{~Bq} / \mathrm{kg}$, from 4.8 to 79.6 $\mathrm{Bq} / \mathrm{kg}$ and from 19.7 to $334.1 \mathrm{~Bq} / \mathrm{kg}$ respectively. The high concentrations of ${ }^{238} \mathrm{U}$ activity might be due to its geological formation.

\subsection{Destructive Analysis}

The concentrations of ${ }^{234} \mathrm{U},{ }^{235} \mathrm{U}$, and ${ }^{238} \mathrm{U}$ as well as activity ratios of ${ }^{234} \mathrm{U} /{ }^{238} \mathrm{U}$, and ${ }^{235} \mathrm{U} /{ }^{238} \mathrm{U}$ measured were shown in Table 2. The specific activities of ${ }^{238} \mathrm{U}$ ranged from 13.2 to $66.1 \mathrm{~Bq} / \mathrm{kg}$ with an average of $37.2 \mathrm{~Bq} / \mathrm{kg}$, while the specific activities of ${ }^{234} \mathrm{U}$ ranged from 13.8 to 62.6 Bq/ $\mathrm{kg}$ with an average of $36.7 \mathrm{~Bq} / \mathrm{kg}$. The ratios of ${ }^{234} \mathrm{U} /{ }^{238} \mathrm{U}$ ranged from 0.94 to $1.05 \mathrm{~Bq} / \mathrm{kg}$ with an average of $0.98 \mathrm{~Bq} / \mathrm{kg}$. A very good correlation $\left(r^{2}=0.998\right)$ exists between ${ }^{234} \mathrm{U}$ and ${ }^{238} \mathrm{U}$ as shown in Figure 4.

The specific activities of ${ }^{235} \mathrm{U}$ were below the detection limit of the system. The isotope ratio involving the minor isotope namely ${ }^{234} \mathrm{U}$, can be obtained with a reasonable accuracy of about $5 \%$, which is promising especially
Table 1. The activity concentration in $(\mathrm{Bq} / \mathrm{kg})$ for the analyzed samples measured by HpGe Detector.

\begin{tabular}{cccc}
\hline Sample & ${ }^{226} \mathrm{Ra}\left({ }^{238} \mathrm{U}\right.$-series $)$ & ${ }^{228} \mathrm{Ra}\left({ }^{232} \mathrm{Th}\right.$-series $)$ & $\mathrm{K}-40$ \\
\hline S1 & $91.1 \pm 3.9$ & $52.0 \pm 1.6$ & $288.0 \pm 6.0$ \\
S2 & $77.2 \pm 3.1$ & $4.8 \pm 0.2$ & $19.7 \pm 1.5$ \\
S3 & $129.9 \pm 5.1$ & $79.6 \pm 2.1$ & $334.1 \pm 6.9$ \\
S4 & $149.0 \pm 5.3$ & $52.0 \pm 1.7$ & $288.2 \pm 6.1$ \\
S5 & $139.3 \pm 5.0$ & $75.6 \pm 1.9$ & $360.8 \pm 3.9$ \\
S6 & $44.9 \pm 3.9$ & $25.3 \pm 1.5$ & $152.8 \pm 5.3$ \\
\hline
\end{tabular}

Table 2. The activity concentration in $(\mathrm{Bq} / \mathrm{kg})$ for the analyzed samples measured by $\alpha$-spectrometry in reference and granite samples.

\begin{tabular}{cccc}
\hline Sample & ${ }^{238} \mathbf{U}$ & ${ }^{234} \mathbf{U}$ & ${ }^{234} \mathbf{U} /{ }^{238} \mathbf{U}$ \\
\hline S1 & $40.3 \pm 1.1$ & $38.4 \pm 1.1$ & 0.95 \\
S3 & $58.6 \pm 1.4$ & $60.2 \pm 2.7$ & 1.02 \\
S6 & $13.2 \pm 0.6$ & $13.8 \pm 0.4$ & 0.95 \\
IAEA-326 & $32.0 \pm 1.4$ & $31.4 \pm 3.4$ & 0.98 \\
IAEA-375 & $13.2 \pm 0.4$ & $13.9 \pm 0.4$ & 1.05 \\
IAEA-300 & $66.1 \pm 4.8$ & $62.6 \pm 5.1$ & 0.94 \\
\hline
\end{tabular}

with lower sample volume.

The validations of the method were tested using IAEA reference materials IAEA-326 (soil), IAEA-375 (soil), and IAEA-300 (sediment) samples. The values obtained were in good agreements with the reference values reported by IAEA indicating robustness of our procedure. 


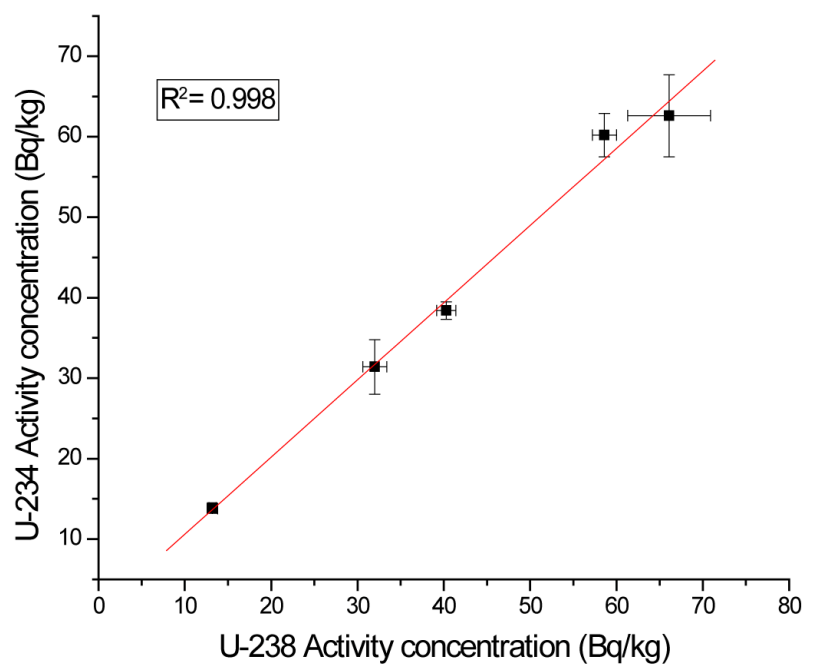

Figure 4. Correlation between U-238 and U-234 measured by alpha spectrometry.

\section{Conclusion}

A simple analytical technique for the determination of uranium isotopes in soil samples was developed and validated by testing several IAEA reference samples. The results obtained using current procedure indicates that these radioactivity concentrations are of natural origin. The isotopic values of approximately one between ${ }^{234} \mathrm{U}$ to ${ }^{238} \mathrm{U}$ indicate secular equilibrium between these two isotopes in the soil samples.

\section{REFERENCES}

[1] P. R. Danesi, A. Bleise, W. Burkart, M. J. Campbell, X. Makarewicz, J. Moreno, C. Tuniz and M. Hotchkis, "Isotopic Composition and Origin of Uranium and Plutonium in Selected Soil Samples Collected in Kosovo," Journal of Environmental Radioactivity, Vol. 64, No. 2-3, 2003, pp. 121-131. http://dx.doi.org/10.1016/S0265-931X(02)00043-7

[2] M. Matolin, "Construction and Use of Spectrometric Calibration Pads Laboratory $\gamma$-Ray Spectrometry, NMA, Egypt. A Report to the Government of the Arab Republic of Egypt," Project EGY/4/030-03, IAEA, 1991.

[3] M. Saïdou, F. Bochud, J.-P. Laedermann, M. G. Kwato Njock and P. Froidevaux, "A Comparison of Alpha and Gamma Spectrometry for Environmental Natural Radioactivity Surveys," Applied Radiation and Isotopes, Vol. 66, No. 2, 2008, pp. 215-222. http://dx.doi.org/10.1016/j.apradiso.2007.07.034

[4] G. Jia, M. Belli, U. Sansone, S. Rosamilia, R. Ocone and S. Gaudino, "The Determination of Uranium Isotopesin Environmental Samples by Alpha-Spectrometry," Journal of Radioanalytical and Nuclear Chemistry, Vol. 253, No. 3, 2002, pp. 395-406. http://dx.doi.org/10.1023/A:1020413302019

[5] F. Abbasisiar, T. Hosseini, A. Fathiv and Gh. Heravi,
"Determination of Uranium Isotopes $\left({ }^{234} \mathrm{U},{ }^{238} \mathrm{U}\right)$ and Natural Uranium (U-nat) in Water Samples by Alpha Spectrometry," Iranian Journal of Radiation Research, Vol. 2, No. 1, 2004, pp. 35-40.

[6] F. V. Tomé, M. P. Blanco Rodríguez and J. C. Lozano, "Study of the Representativity of Uranium and Thorium Assays in Soil and Sediment Samples by Alpha Spectrometry," Applied Radiation and Isotopes, Vol. 56, No. 1-2, 2002, pp. 393-398.

http://dx.doi.org/10.1016/S0969-8043(01)00220-2

[7] F. V. Tome and A. M. Sanchez, "Optimizing the Parameters Affecting the Yield and Energy Resolution in the Electrodeposition of Uranium," International Journal of Radiation Applications and Instrumentation. Part A. Applied Radiation and Isotopes, Vol. 42, No. 2, 1991, pp. 135-140.

http://dx.doi.org/10.1016/0883-2889(91)90062-6

[8] V. Tsoupko-Sitnikov, F. Dayras, J. de Sanoit and D. Filossofov, "Application of Rotating Disk Electrode Technique for the Preparation of $\mathrm{Np}, \mathrm{Pu}$ and $\mathrm{Am} \alpha$ Sources," Applied Radiation and Isotopes, Vol. 52, No. 3, 2000, pp. 357-364. http://dx.doi.org/10.1016/S0969-8043(99)00178-5

[9] E. García-Toraño, "Current Status of Alpha-Particle Spectrometry," Applied Radiation and Isotopes, Vol. 64, No. 10-11, 2006, pp. 1273-1280. http://dx.doi.org/10.1016/j.apradiso.2006.02.034

[10] M. Acena, M. Crespo, M. Galan and J. Gascon, "Determination of Isotopes of Uranium and Thorium in LowLevel Environmental Samples," Nuclear Instruments and Methods in Physics Research Section A: Accelerators, Spectrometers, Detectors and Associated Equipment, Vol. 339, No. 1-2, 1994. pp. 302-308.

[11] C. Galindo, L. Mougin and A. Nourreddine, "An Improved Radiochemical Separation of Uranium and Thorium in Environmental Samples Involving Peroxide Fusion," Applied Radiation and Isotopes, Vol. 65, No. 1, 2007, pp. 9-16. http://dx.doi.org/10.1016/j.apradiso.2006.05.012

[12] M. S. El-Tahawy, M. A. Farouk, F. H. Hammad and N. M. Ibrahim, "Natural Potassium as a Standard Source for the Absolute Efficiency Calibration of Germanium Detectors," Journal of Nuclear Science, Vol. 29, No. 1, 1992, pp. 361-363.

[13] R. Higgy, A. Khater and M. Pimpl, "Procedures Manual, Radiochemical Analysis of Certain Naturally Occurring and Man-Made Radionuclides in Environmental Samples," AEA Internal Report No. 310, 2003.

[14] M. Pimpl, B. Yoo and I. Yordanova, "Optimization of a Radioanalytical Procedure for the Determination of Uranium Isotopes in Environmental Samples," Journal of Radioanalytical and Nuclear Chemistry, Vol. 161, No. 2, 1992, pp. 437-441. http://dx.doi.org/10.1007/BF02040490

[15] N. M. Ibrahiem and M. Pimpl, "Uranium Concentrations in Sediments of the Suez Canal," Applied Radiation and Isotopes, Vol. 45, No 9, 1994, pp. 919-921. http://dx.doi.org/10.1016/0969-8043(94)90228-3 